\title{
Implementation of an Android Application for Crime Prediction and Highlighting Vulnerable Areas of a City
}

\author{
${ }^{1}$ Deepika Dhakad, ${ }^{2}$ Utkarsh Khosla, ${ }^{3}$ Vipul Singh Jaiswar, ${ }^{4}$ Margi Patel \\ ${ }^{1,2,3}$ B.Tech. Scholars, ${ }^{4}$ Assistant Professor, Dept. of Computer Science \& Engineering, Indore \\ Institute of Science and Technology, Indore MP, India. \\ 1dhakad3079deepika@gmail.com, ${ }^{2}$ utkarshkhosla18@gmail.com, 3vipul05sep1999@gmail.com, \\ ${ }^{4}$ margi.patel22@gmail.com
}

\begin{abstract}
Crime is one of the most daunting and intimidating challenge in our society. With the majority of population residing in cities many experts and data provided by the local authorities insinuate a proliferate growth of crimes committed in these cities in last few years. Crime prediction and criminal identification pose major problems for the police department as there is tremendous amount of criminal data that exist and is made available by the police. There is a need of a robust application which will help local authorities, the inhabitants of the city and the tourists. This paper focuses on designing and implementation of an android application for identifying areas of a city which are more threatened by frequent occurrence of criminal activities and various other criminal misdemeanor. By means of this application we want to play our part in accordance with the local authorities to increase and ensure the safety of denizens of a city and tourists currently in a city. Our dataset is extracted from the local authorities of Indore. It consists of relevant information like location of crime occurred, description of crime, type of crime, date, time, latitude, longitude, classification of crime. Users will have to create accounts with their credentials. We have managed to create a user friendly software which also provides haptic feedback to the user. A user will be able to identify the venturesome areas all around their city along with the various precautionary measures that should be practiced whilst they are present in a particular vulnerable area. Our app will also be able to harbinger the type of crime that may happen in a specific region in the future. Our application will also consist of various other significant features like safety audit, SOS signal generation, emergency contacts, feedback from the denizens of a city.
\end{abstract}

Keywords: Safety audit, Google maps, Vulnerable or venturesome areas, Crime prediction, Emergency contacts, Alert system, Safety measures.

\section{INTRODUCTION}

Safety is a major issue in today's world. While you are inside your home there can be some unfortunate criminal incident occurring around your area. Our mission is to help civilians of a city and also the tourist identifies the venturesome areas of the city and try to increase the safety of people residing in these area or the people currently present in that region. There is data available in cities, which indicates a particular section being more unsafe than others. Therefore, with the help of this data, we intend to make a real-time android application for ensuring the safety of the citizens of the city by giving them alert to prone areas with safety measures they could take. The app will also be useful in the case of Emergency. So, this is why we need this Crime Prediction Application.

\section{Related Work}

The proposed project is a combination of two or more existing systems that are in the market, hence it is a hybrid project and hence is not available in the market.

In other words, the proposed project contains features that does not preexist or are not available in a single mobile application.

\section{Literature REVIEW}

Many countries have already recognized that with the crime rate increasing almost everywhere technologies like artificial intelligence, machine learning, data analytics, android applications and many more of these evolving fields and can help the law enforcement agencies decrease 
criminal activities and possibly predict the exact details of a malefaction before it has actually occurred. This concept of prognosticating offence before it has actually occurred is very intuitive and most of all very intriguing. Highlighting the areas which are worse affected by constant different kinds of criminal misdemeanor and some really grave offences can help and save the lives and properties of millions. Through this application we got the chance to achieve this purpose and contribute to our society. [1]We also came across a company which is doing something similar to our application. It is being used in United Kingdom known as PredPol - short for predictive policing but it is not available in India and is not predicting the venturesome areas in a city by any means but is only predicting the crime details before it actually occurs[1].

[2]In October 2019 India's National Crime Records Bureau (NCRB) submitted the crime report containing statistics relating to urban crime in India which enlighten us the crime rate in different cities[2].

Our research also brought some more facts about urban crime in in India. These are as follows-

1. [3] Over half of the Indians are unlikely to recognize an unsafe area while travelling to another city.

2. Lack of awareness and lack of vigilance is a major reason why crimes rate is increasing in every city in India.

3. In 2015, almost 10 out of every $1,00,000$ foreign tourists in India were victims of crime.

4. Following graph shows the crime rate in different cities in 2017[3].

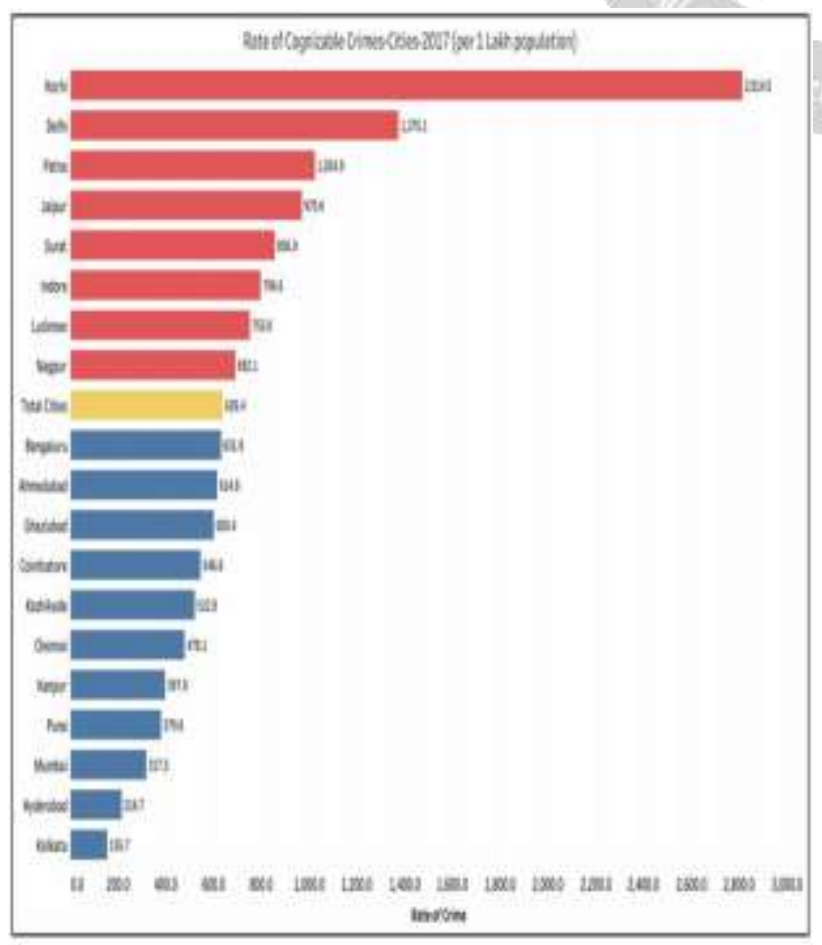

5. [4]Over $65 \%$ Of Crimes Against Foreign Tourists Are Theft.

6. Following graph shows the crime against foreigners in 2015[4].

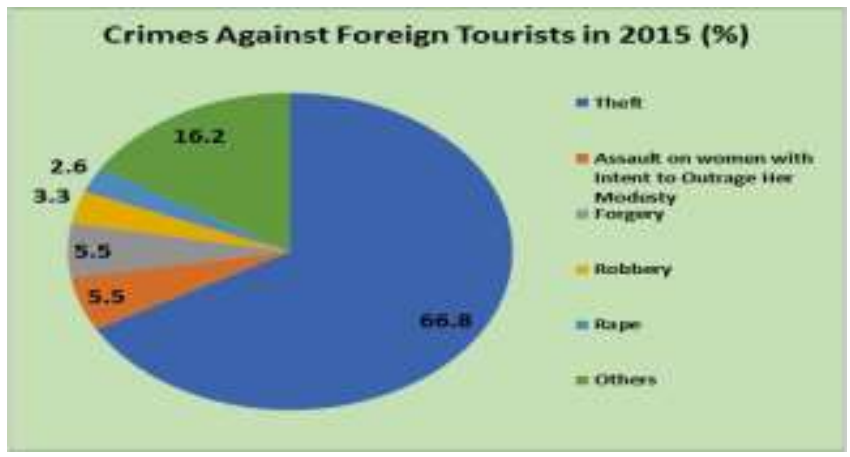

\section{PROPOSED WORK}

Our application displays all the crime vulnerable areas near the user's location and also in the city along with the classification of crimes committed in a region. Our application will also consider the opinions of citizens residing in a region before highlighting an area vulnerable to criminal activities.

Crimes are of different types robbery, murder, rape, assault, battery, false imprisonment, kidnapping, homicide. Our application predicts the unsafe areas of cities using the dataset and on the basis of this observation, we will flag an area unsafe using various colour schemes to distinguish between different types of crime. Also we will provide information about the frequency of crime in an area at day and at night. Before marking an area venturesome or unsafe we will also communicate with the people residing in that area to make sure they concur with us. Our dataset is acquired from Indore Police so it is credible and accurate. The application will be available across various types of android devices like smartphones, smart watches etc. If a user enters an unsafe area safety measures and a notification will be provided to the him or her. If the user is in any kind of danger a SOS signal will be generated by which the emergency contacts of the user will be alerted and also address of nearest police station will be displayed on the application along with the address of nearest medical service. Our application continuously learns from the updated dataset and becomes capable of predicting types of crime occurring in an area in the future and also if the rate of crime eventually decreases in a region it will be removed from an unsafe area and categorized as a safe area. Also the application will also provide a feature known as safety audit which will basically ask the user who visited a venturesome area about their experience while there were present there. The response of various user will also be used as a different dataset for foretelling crime that might happen in the future in a particular area. 
We will also consider and value the opinions of a user about how safe they feel in their own neighbourhood.

\subsection{Scope}

This application helps us address the current safety issues faced by denizens of a city and also the tourist visiting a particular city for the first time. We want to help enlighten a user about various types of crimes that might occur in their city and how they can ensure their own safety in the areas which are threatened by frequent criminal activities. We are really optimistic that this application can help the police and other various other law enforcement agencies decrease the exceptionally high crime rate. During our research we also observed that in the past few years there has been a significant growth in the number of crimes committed against tourist which really hurts the tourism industry and also it jeopardizes the reputation of our country which has a long standing history of treating its tourists like god. We want to help these tourists identify the unsafe areas in a city which they are currently visiting and help them maintain their own safety. Locals of a city especially the people residing in metro cities are often found to be not aware about the history of crimes committed in various places in their city, our application once fully functional will help them stay cautious when they are in an unsafe area along with the necessary precautionary measures they should follow for the sake of their own safety. While helping every user that registers on our apps we do not want people residing in an area to be offended when our application marks their neighborhood to be potentially vulnerable to criminal activities, for this reason our application includes a safety audit so that people can tell us more about their vicinity and how safe they feel around their homes and neighborhood so we can solve this dilemma about flagging their area safe or unsafe.

\section{DEVELOPMENT METHOD}

For developing this application, we have applied Iterative model. The Iterative model, iterative process starts with a simple implementation of a small set of the software requirements and iteratively enhances the evolving versions until the complete system is implemented and ready to be deployed.

An iterative life cycle model does not attempt to start with a full specification of requirements. Instead, development begins by specifying and implementing just part of the software, which is then reviewed to identify further requirements. This process is then repeated, producing a new version of the software at the end of each iteration of the model.

The iterative approach encompasses the following phase:

\section{- Testing}

\section{- Evaluation}

- Requirement gathering \& analysis: As with most any development project, the first step is go through an initial planning stage to map out the specification documents, establish software or hardware requirements, and generally prepare for the upcoming stages of the cycle.

- Analysis \& Design: Once planning is complete, an analysis is performed to nail down the appropriate business logic, database models, and the like that will be required at this stage in the project. The design stage also occurs here, establishing any technical requirements (languages, data layers, services) that will be utilized in order to meet the needs of the analysis stage.

- Implementation: With the planning and analysis out of the way, the actual implementation and coding process can now begin. All planning, specification, and design docs up to this point are coded and implemented into this initial iteration of the project.

- Testing: Once this current build iteration has been coded and implemented, the next step is to go through a series of testing procedures to identify and locate any potential bugs or issues that have cropped up.

- Evaluation: Once all prior stages have been completed, it is time for a thorough evaluation of development up to this stage. This allows the entire team, as well as clients or other outside parties, to examine where the project is at, where it needs to be, what can or should change, and so on.

[5]This is the crux of the entire iterative model, whereby the most recently built iteration of the software, as well as all feedback from the evaluation process, is brought back to the planning \&amp; development stage at the top of the list, and the process repeats itself all over again[5].
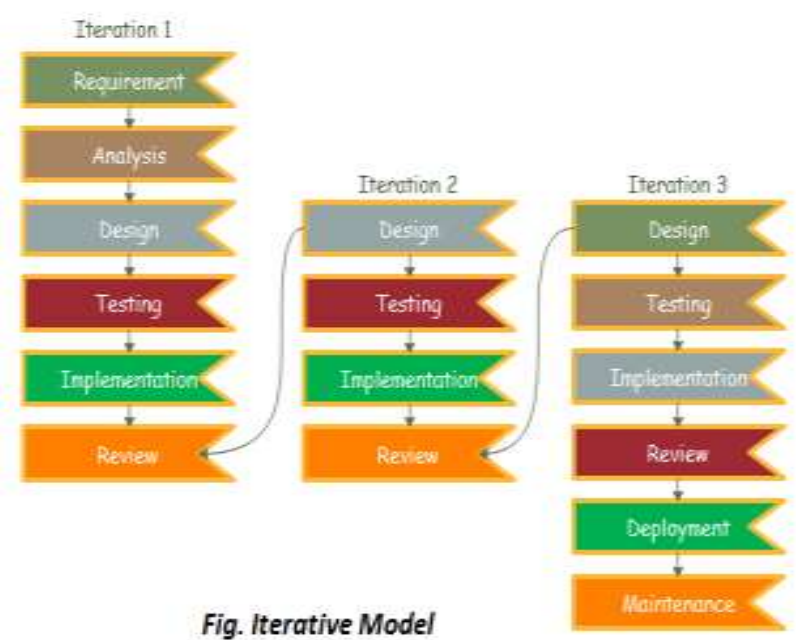

Fig. Iterative Model

- $\quad$ Requirement gathering $\&$ analysis

- Design

- Implementation 


\section{EXPERIMENTAL RESUlts}

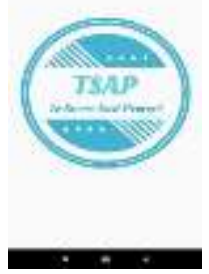

Fig. 1: Welcome-Page

This is the welcome page for the user. The layout of the page displays logo and the name of the app. The name of our app is TSAP that stands for, to serve and protect.

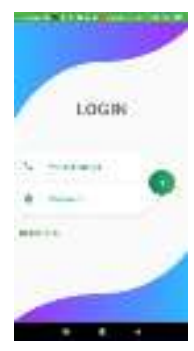

Fig. 2: Login-Page

Fig. 3: Home-Page

As soon as we login into our account it will ask the user's permission to access their location and automatically detect their location and once access is granted. After knowing user's location, the app will match this location to the dataset of unsafe areas and will notify the user accordingly.

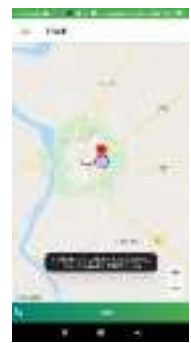

Fig. 4: User-Location

After detecting the location of the user app will show the area around this location. This will help the user recognize the unsafe area around their current location and the location of a nearby police precinct.

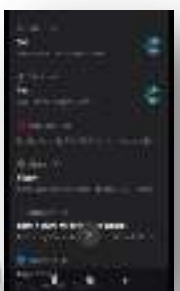

In this page first a user has to provide their required credentials to register. After successfully registering user can login through this login page in their account using the registered phone number and the password. This will take us to the home page.

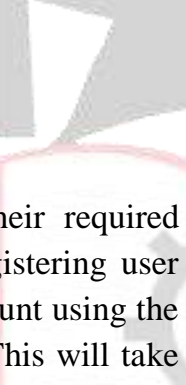

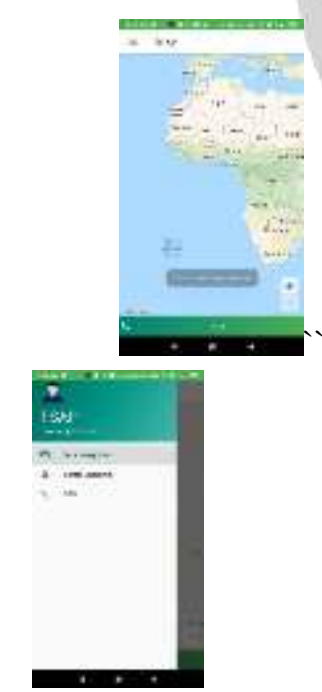

Fig. 6: Sliding-Window

In the main menu three options are available.

These are:

1) Do a safety audit

2) Safety Measures

3) Emergency call or SOS.
Fig. 5: Alert and Notifications

If the user is near or in an unsafe area an alert or notification will be generated on the user's device showing 'you are near a perilous area' or 'you are currently in an unsafe area' so that user is vigilant and aware about their own safety while they are present in that area.

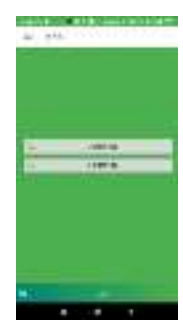

Fig. 8: SOS-Page

This SOS page stores the emergency

number and the contact details of user's

friends and family so that the user can call them

In any emergency and receive their assistance 


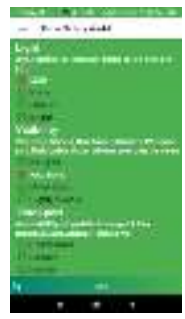

Fig 7: Safety-audit Page

In this page a user can fill a safety audit form for their considering their opinion on to what extent they

feel safe near their own residence. This page basically displays

a form asking a user about availability of light, visibility in day

and night and accessibility of public transport in their vicinity

\section{CONCLUSION}

This paper presents the design and implementation of an android application for highlighting prone areas and future crime prediction. The proposed application that is developed can ensure safety of inhabitants and especially tourist in a city also it spreads a lot of awareness about different types of crimes that might occur in an area. During this project we gained an insight about types of crime, crime rate and part of the cities which are safe and unsafe and got a chance to reduce this and make our city safer. We have also received a very positive response from local authorities for this app while interacting with them for acquiring the dataset of unsafe parts of cities. We have also gained an insight about urban crime in our research and how as a software engineers we can create intriguing applications for empowering our society and our country.

\section{FUTURE SCOPE}

In the near future we will also introduce a system of filing Pre-FIR. which will be helpful for both the person filling it and for the local authorities to respond to a situation. And for the safety of the citizens in case of any emergency we will try to introduce Emergency Drone system, which will respond and react according to the situation in case of any emergency. Registering application with Google service and uploading it into Google Play Store.

\section{REFERENCES}

[1] https://www.bbc.com/news/business-46017239 accessed on 15 April 2020

[2] https://www.orfonline.org/expert-speak/an-analysis-ofcrime-in-indias-largest-urban-agglomerations-57166/ accessed on 15 April 2020

[3] https://factly.in/what-is-the-status-of-crime-in-19-ofthe-large-indian-cities/ accessed on 17 April 2020

[4] https://www.boomlive.in/over-65-of-crimes-againstforeign-tourists-are-theft-a-data-fact-file/ accessed on 17 April 2020

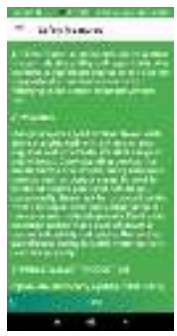

Fig. 8: Safety-Measures Page

In the above page all the safety measures are provided neighbourhood by that one should take when they are in an unsafe area

In case of any emergency, safety-measures would be of great help to the user in dealing with any situation.

[5] https://www.javatpoint.com/software-engineeringiterative-model accessed on 18 April 2020

[6] J. Dongjiu Geng, Yue Suo, Yu Chen, Jun Wen, Yongqing Lu, Remote Access and Control System Based on Android Mobile Phone vol.2. Journal of Computer Applications, 2011, pp. 560-562.

[7] Jose DV, Lakshmi Priya C, Priyadarshini G \& Singh M, "Challenges and Issues in Android App Development-An Overview", International Journal of Advanced Research in Computer Science and Software Engineering, Vol.5, No.1, (2015).

[8] Barry Burd, Android App Development for Dummies: Concepts and techniques to Design Android App. 